Editorial

\section{Controlling the obesity epidemic is important for maintaining musculoskeletal health}

\section{A D Woolf, F C Breedveld, T K Kvien}

\section{Obesity: the risks on musculoskeletal health}

\section{OBESITY - THE GROWING EPIDEMIC}

Awareness of the importance of obesity and an urgency for action in view of the increasing numbers of people of excess weight at all ages is increasing. The focus is on the effect of obesity on conditions with high morbidity and mortality-for example, coronary heart disease, ischaemic stroke, type 2 diabetes and cancers, whereas the effect on osteoarthritis, back pain and other musculoskeletal problems ${ }^{2}$ is underappreciated. Although obesity is recognised as contributing to the burden of osteoarthritis, ${ }^{1}$ the potential benefits for musculoskeletal health of maintaining an ideal body weight are not recognised. ${ }^{3}$ There is strong evidence that obesity is a major determinant of osteoarthritis Consequently, maintaining an ideal body weight at all ages is a major recommendation of the European Action Towards Better Musculoskeletal Health Report and of the American College of Rheumatology and European League Against Rheumatism guidelines for osteoarthritis..$^{5-7}$

Obesity is a major concern in Europe as Europe has one of the highest body mass indices (BMIs (weight $(\mathrm{kg}) /\left(\right.$ height $^{2}$ $\left.\left.(\mathrm{m})^{2}\right)\right)$ ) of all regions under the World Health Organization, with 400 million adults estimated to be overweight and 130 million to be obese. ${ }^{68}$ The prevalence of obesity has risen threefold or more in many European countries since the 1980s. The main contributors to this increase are unhealthy diets and physical inactivity. In view of the actions being taken to combat this epidemic of obesity, there is a need for better recognition of the effect of obesity on the musculoskeletal problems. The forthcoming World Health Organization European Region Ministerial Conference on Counteracting Obesity is a forum to ensure the development of an integrated strategy that considers all the effects of obesity and the problems of controlling and reducing obesity in a physically inactive and ageing population.

What is the evidence of the role of obesity in osteoarthritis, and what should be the recommendations for how lifestyle measures such as exercise and weight control can be used to reduce the burden of musculoskeletal problems?

\section{OBESITY AND OSTEOARTHRITIS}

Obesity is a major risk factor for the occurrence, progression and effect of osteoarthritis-the fifth leading cause of loss of healthy life in high-income countries. $^{2}$ Osteoarthritis of the knee makes a major contribution to this. The risk for osteoarthritis of the knee was increased almost fourfold in obese women and 4.8fold in obese men whose BMI was in the range 30-35 compared with those whose BMI was $<25$ in the first National Health and Nutrition Examination survey. ${ }^{9}$ The risk for osteoarthritis of the knee is increased by approximately 15\% for each additional $\mathrm{kg} / \mathrm{m}^{2}$ increase in BMI $>27$. Other studies have found similar associations, although some have shown the risk to be greater in women.

Obesity has been found to precede osteoarthritis of the knee and is therefore not just a consequence of reduced mobility, although this will also contribute. People who are overweight in their mid30s have been shown to be at increased risk of developing osteoarthritis of the knee when in their 70s, ${ }^{10}$ and longitudinal population studies have shown that initial weight correlates with risk of future development of osteoarthritis, both in the tibiofemoral and patellofemoral compartments. ${ }^{11}$ Obese people are particularly at risk of bilateral osteoarthritis of the knee.

The progression of osteoarthritis of the knee is also increased with obesity, ${ }^{12}$ and obesity is a risk factor for progression from unilateral to bilateral osteoarthritis of the knee. ${ }^{13}$

Obesity is also a risk factor for the occurrence of osteoarthritis of the hip, most consistently found for symptomatic disease and not just radiological changes, ${ }^{14}$ but the association is not as strong as for osteoarthritis of the knee. It may be that obesity induces symptoms in people with osteoarthritis of the hip or that the weakness of association is a result of difficulties with the radiographic identification of early changes. Interestingly, a weak association between obesity and osteoarthritis of the hand has also been shown in some studies. ${ }^{15}$

The primary mechanism for osteoarthritis in obesity is the effect of overloading the hip and knee joints during weight-bearing activities. Metabolic factors associated with obesity may also have a role, which may explain the association with osteoarthritis of the hand.

\section{WEIGHT REDUCTION AND OSTEOARTHRITIS}

Obesity clearly contributes to the effect of osteoarthritis by increasing the incidence, progression and loss of activities, and participation, but can weight reduction reduce the burden? Evidence comes from epidemiological and a limited number of interventional studies.

The Framingham study has shown that a decrease in BMI of $\geqslant 2$ units in women over the previous 10 years decreased the odds of developing osteoarthritis of the knee by over $50 \%$ (odds ratio (OR) 0.46 , 95\% confidence interval (CI) 0.24 to $0.86) .{ }^{16}$ The risk of osteoarthritis of the knee in women with increased baseline BMI also decreased by almost $60 \%$ with $\geqslant 2$ units of BMI loss. In women free of disease at baseline, a higher BMI increased the risk of osteoarthritis (OR 1.6 (per 5-unit increase), 95\% CI 1.2 to 2.2 ), and weight change was directly correlated with risk of osteoarthritis (OR 1.4 (per 10-pound change in weight), 95\% CI 1.1 to 1.8$).{ }^{17}$

Few therapeutic trials have examined the effect of weight loss in osteoarthritis of the knee. Knee pain was less often reported after gastric stapling (14\% of subjects $v 54 \%$ of subjects before this procedure), with a mean weight loss of $45 \mathrm{~kg}$ in an uncontrolled study. ${ }^{18}$ Huang et $a l^{19}$ found that patients with osteoarthritis of the knee and obesity who were allocated to receive a weight reduction intervention (including weekly auricular acupuncture, diet control and aerobic exercise) with or without ultrasound, and transcutaneous electric stimulation treatment successfully lost weight and had greater pain reduction and improvement in Lequesne index than patients who received only ultrasound and transcutaneous electric stimulation. The weight loss and the speed of ambulation were less in those with more severe osteoarthritis, suggesting that reduced physical activity probably has a role in excess weight and difficulty in weight reduction. A further short-term non-randomised trial has shown the benefits of diet and exercise in overweight Japanese women with osteoarthritis of the knee. ${ }^{20}$ Messier et a ${ }^{21}$ compared exercise and weight reduction with exercise alone in older patients with osteoarthritis of the knee and found that both groups lost weight and had marked improvement in pain and disability. This group of researchers subsequently 
reported the first large randomised clinical trial, Anti-Inflammatory Prevention Trial, assessing the symptomatic benefit of weight loss and exercise separately or in combination in overweight and obese sedentary older people with disabling osteoarthritis of the knee ove 18 months. ${ }^{22}$ The average weight loss was $5.7 \%$ in the diet and exercise group and $4.9 \%$ in the diet alone group, in contrast with $1.2 \%$ in the group just educated about following a healthy lifestyle. Diet in combination with exercise was most effective in improving self reported measures of function and pain whereas diet alone had a benefit on selfreported physical function (Western Ontario and Mcmasters University Osteoarthritis Index). This study not only shows the benefit of weight reduction and exercise but also highlights the need for supervision rather than just education.

Although there is an epidemiological association between osteoarthritis of the hip and obesity, ${ }^{14}$ there is no randomised controlled trial evidence of a benefit of weight loss in patients with osteoarthritis of the hip.

\section{OBESITY AND OSTEOARTHRITIS- THE RECOMMENDATIONS}

Clearly, there is a strong association between obesity and osteoarthritis of the lower limbs, and evidence that avoidance of obesity or reduction in weight will reduce the incidence, progression and effect, in particular, of osteoarthritis of the knee. Stronger evidence is still needed of the long-term benefits and feasibility of this approach, but there is sufficien evidence and expert opinion that weight reduction is recommended in the European Action Towards Better Musculoskeletal Health Report, ${ }^{4}$ as well as in the American College of Rheumatology and European League Against Rheumatism recommendations for management of osteoarthritis. ${ }^{5-7}$ Exercise is also effective in the management of osteoarthritis. ${ }^{23}$ Clearly, it is most effective to combine weight reduction with exercise, and therefore this combined approach needs to be encouraged and facilitated. Many patients with lower limb osteoarthritis are concerned about undertaking exercise in case it worsens their condition, or if they are unable to exercise due to aggravation of symptoms. People with such concerns will need explanation with reassurance and good pain management.

\section{THE CHALLENGE}

Obesity is a major threat to many aspects of health, including musculoskeletal aspects. Preventing obesity along with encouraging physical activities and maintaining physical function are important strategies. Recognising the mutual benefits of this strategy for several non-communicable diseases will also enable the development of better ways of implementing them. We need to focus on how to improve diets and physical activity to control obesity and improve the quality of life.

Public health strategies need to focus on healthy people, including children, but focus should also be directed to people who already have joint problems and limited physical function due to lower limb joint diseases. People of all ages should be the target population, but people are most likely to change their behaviour with the occurrence of a trigger event such as the first episode of knee pain. Such an event may be an opportunity for a proactive approach to improve lifestyle. Further, healthcare providers should raise their awareness about obesity when considering secondary and tertiary preventive measures in patients with joint diseases. It is essential to have a single message about the importance of diet, weight and level of physical activity for all the different conditions they may benefit. "United we stand, divided we fall". Thus, providers of healthcare in the field of musculoskeletal diseases must work with public health physicians, cardiologists, oncologists, diabetologists and health promoters, along with health policy makers, to ensure that changing lifestyle factors improves all aspects of health.

Ann Rheum Dis 2006;65:1401-1402.

doi: 10.1136/ard.2006.058172

\section{Authors' affiliations}

A D Woolf, Department of Rheumatology, Royal

Cornwall Hospital, Truro, UK

T K Kvien, Department of Rheumatology,

Diakonhiemmet Hospital, Oslo, Norway

F Breedveld, Department of Rheumatology,

Leiden University Medical Centre, The

Netherlands

Correspondence to: A D Woolf, Rheumatology Unit, Royal Cornwall Hospital, Truro TR1 3L, UK; anthony.woolf@btopenworld.com

Accepted for publication 18 July 2006

\section{REFERENCES}

1 World Health Organization. World Health Report 2002. Reducing risks, promoting health lives. Geneva: World Health Organization, 2002 http://www.who.int/whr/2002/en/ whr02_en.pdf (accessed 4 Aug 2006).

2 Lopez AD, et al. Global burden of disease and risk factors. New York: Oxford University Press, 2006, http://www.dep2.org/pubs/GBD (accessed 4 Aug 2006).

3 WHO Regional Office for Europe. The European Health Report 2005. Public health action for healthier children and populations. Copenhagen: WHO Regional Office for Europe, 2005, http://wmw. euro.who.int/ehr2005 (accessed 4 Aug 2006).

4 European Bone and Joint Health Strategies Project. European action towards better musculoskeletal health. Lund, Sweden: Bone and Joint Decade, 2004, http://www.osteofound.org/ health_professionals/csa_working_groups/pdf/ eu_action_2004.pdf (accessed 4 Aug 2006).
5 Altman RD, Hochberg MC, Moskowitz RW, Schnitzer TJ. Recommendations for the medical management of osteoarthritis of the hip and knee: 2000 update. Arthritis Rheum 2000:43:1905-15.

6 Pendleton A, Arden N, Dougados M, Doherty M, Bannwarth B, Bijlsma JW, et al. EULAR recommendations for the management of knee osteoarthritis: report of a task force of the Standing Committee for International Clinical Studies Including Therapeutic Trials (ESCISIT). Ann Rheum Dis 2000;59:936-44.

7 Zhang W, Doherty M, Arden N, Bannwarth B $\mathrm{Bijl}$ sma J, Gunther KP, et al. EULAR evidence based recommendations for the management of hip osteoarthritis: report of a task force of the EULAR Standing Committee for International Clinical Studies Including Therapeutics (ESCISIT). Ann Rheum Dis 2005:64:669-81.

8 World Health Organization. The challenge of obesity in the WHO European Region. WHO Fact Sheet EURO/13/05. 2005. http:// www.euro.who.int/document/mediacentre/ fs 1305e.pdf (accessed 4 Aug 2006)

9 Anderson JJ, Felson DT. Factors associated with osteoarthritis of the knee in the first national Health and Nutrition Examination Survey (HANES I). Evidence for an association with overweight race, and physical demands of work. Am J Epidemiol 1988;128:179-89.

10 Felson DT. Epidemiology of hip and knee osteoarthritis. Epidemiol Rev 1988;10:1-28.

11 McAlindon T, Zhang Y, Hannan M, Naimark A Weissman B, Castelli W, et al. Are risk factors for patellofemoral and tibiofemoral knee osteoarthritis different? J Rheumatol 1996;23:332-7.

12 Dougados M, Gueguen A, Nguyen M, Thiesce A, Listrat $V$, Jacob $L$, et al. Longitudinal radiologic evaluation of osteoarthritis of the knee. J Rheumatol 1992;19:378-84.

13 Spector TD, Hart DJ, Doyle DV. Incidence and progression of osteoarthritis in women with unilateral knee disease in the general population: the effect of obesity. Ann Rheum Dis 1994;53:565-8

14 Lievense AM, Bierma-Zeinstra SM, Verhagen AP van Baar ME, Verhaar JA, Koes BW. Influence of obesity on the development of osteoarthritis of the hip: a systematic review. Rheumatology (Oxford) 2002;41:1155-62.

15 Carman WJ, Sowers M, Hawthorne VM, Weissfeld LA. Obesity as a risk factor for osteoarthritis of the hand and wrist: a prospective study. Am J Epidemiol 1994; 139:1 19-29.

16 Felson DT, Zhang Y, Anthony JM, Naimark A, Anderson JJ. Weight loss reduces the risk for symptomatic knee osteoarthritis in women. The Framingham Study. Ann Intern Med 1992; 116:535-9.

17 Felson DT, Zhang Y, Hannan MT, Naimark A, Weissman B, Aliabadi $P$, et al. Risk factors for incident radiographic knee osteoarthritis in the elderly: the Framingham Study. Arthritis Rheum 1997; 40:728-33.

18 McGoey BV, Deitel M, Saplys RJ, Kliman ME. Effect of weight loss on musculoskeletal pain in the morbidly obese. J Bone Joint Surg $\mathrm{Br}$ 1990:72:322-3.

19 Huang $\mathrm{MH}$, Chen $\mathrm{CH}$, Chen TW, Weng MC Wang WT, Wang YL. The effects of weight reduction on the rehabilitation of patients with knee osteoarthritis and obesity. Arthritis Care Res 2000; 13:398-405.

20 Toda $Y$. The effect of energy restriction, walking, and exercise on lower extremity lean body mass in obese women with osteoarthritis of the knee. J Orthop Sci 2001;6:148-54.

21 Messier SP, Loeser RF, Mitchell MN, Valle G Morgan TP, Rejeski WJ, et al. Exercise and weight loss in obese older adults with knee osteoarthritis: a preliminary study. J Am Geriatr Soc 2000;48:1062-72.

22 Messier SP, Loeser RF, Miller GD, Morgan TM, Rejeski WJ, Sevick MA, et al. Exercise and dietary weight loss in overweight and obese older adults with knee osteoarthritis: the Arthritis, Diet, and Activity Promotion Trial. Arthritis Rheum 2004;50:1501-10.

23 van Baar ME, Assendelft WJ, Dekker J Oostendorp RA, Biilsma JW. Effectiveness of exercise therapy in patients with osteoarthritis of the hip or knee: a systematic review of randomized clinical trials. Arthritis Rheum 1999;42:1361-9. 